\title{
Sistem Prediksi Pertandingan Sepak Bola Dengan Metode Analytical Hierarchy Process (AHP)
}

\author{
Daniel Walangare ${ }^{(1)}$ \\ danielwalangare@gmail.com
}

\author{
Rosa Delima ${ }^{(2)}$ \\ rosadelima@ukdw.ac.id
}

\author{
Restyandito ${ }^{(3)}$ \\ dito@ukdw.ac.id
}

\begin{abstract}
The problem addressed in this research is how to predict the winner of football match with various criteria. The problem will be solved using Analytic Hierarchy Process (AHP) method. The AHP method that implemented to solve the problems will run two analysis to get an alternative solution. The first AHP method is criteria analysis, in order to get priority vector value. In criteria analysis, to know the consistency of criteria value filling, $C R<10 \%$. If known that criteria value filling not consistant, the process must be repeated until $C R<10 \%$. Then continue with alternate analysis to get global priority vector value wich is AHP solution. The accuration of this system is close to $80 \%$ compare with the real condition.
\end{abstract}

Key word: Analytic Hierarchy Process, AHP, Prediction.

\section{PENDAHULUAN}

Metode Analytic Hierarchy Process (AHP) merupakan sebuah metode yang memodelkan permasalahan kompleks dan tidak terstruktur ke dalam bentuk permasalahan secara bertingkat/berjenjang, kemudian elemen-elemen pada setiap tingkatan akan diberikan penilaian secara kualitatif subyektif. Metode ini cukup banyak digunakan untuk menyelesaikan permasalahan yang berhubungan dengan pengambilan keputusan atau kelayak suatu usaha. Dalam penelitian ini penulis menerapakn metode AHP untuk sebuah sistem prediksi hasil pertandingan sepak bola.

Hasil pertandingan sepakbola merupakan suatu hal yang tidak bisa diperkirakan dengan pasti, tetapi dari data-data pertandingan dapat diketahui adanya suatu pola yang dapat digunakan untuk memperkirakan hasil dari suatu pertandingan. Kebutuhan akan peta kekuatan calon lawan dari tim yang akan bertanding, dengan tujuan untuk meraih kemenangan sangat beralasan. Dengan mengetahui peta kekuatan lawan, sebuah tim khususnya seorang pelatih dapat mempersiapkan dan mengantisipasi kekuatan tim calon

\footnotetext{
${ }^{(1)}$ Teknik Informatika, Fakultas Teknologi Informasi, Universitas Kristen Duta Wacana, Yogyakarta

${ }^{(2)}$ Teknik Informatika, Fakultas Teknologi Informasi, Universitas Kristen Duta Wacana, Yogyakarta

${ }^{(3)}$ Teknik Informatika, Fakultas Teknologi Informasi, Universitas Kristen Duta Wacana, Yogyakrata
} 
lawannya serta dapat memikirkan sebuah strategi dan instruksi-instruksi khusus kepada para pemainnya. Melalui sistem ini pengguna dapat melihat prediksi hasil pertandingan sepak bola dan kekuatan dari masing-masing tim yang akan bertanding.

\section{LANDASAN TEORI}

\subsection{Analytic Hierarchy Process (AHP)}

Analytical Hierarchy Process (AHP) diperkenalkan oleh Thomas L. Saaty pada tahun 1970 an, untuk menyelesaikan masalah multikriteria yang kompleks menjadi suatu hirarki. Tiga prinsip yang harus dipahami untuk menyelesaikan suatu permasalahan dengan metode AHP, yaitu: decomposition, comparative judgement, dan logical consistency.

\section{Decomposition}

Decomposition adalah memecah persoalan yang utuh menjadi unsur-unsur yang saling berhubungan, dalam bentuk struktur hirarki seperti tampak pada gambar 1 .

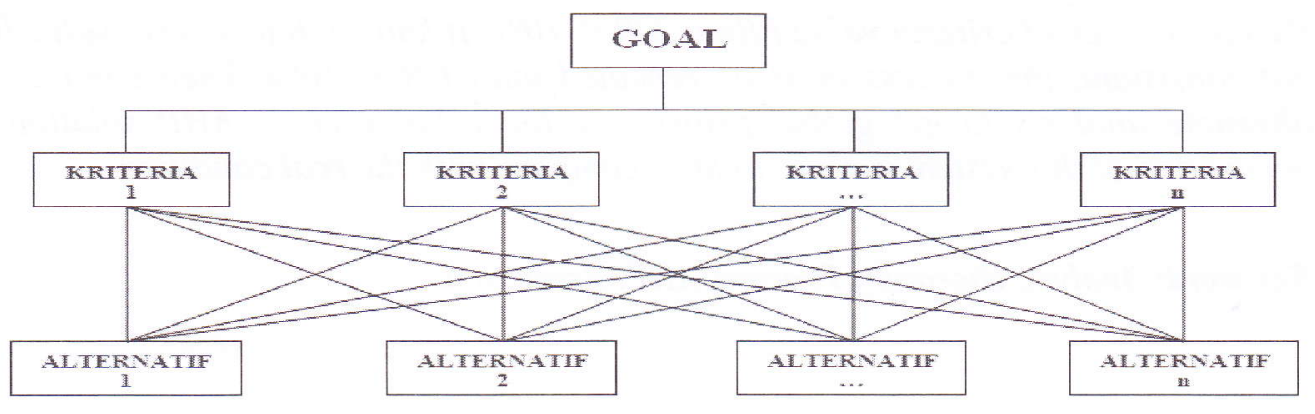

Gambar 1. Gambar Stuktur Hirarki

2. Comparative Judgement

Comparative judgement dilakukan dengan memberikan penilaian tentang kepentingan relatif dua elemen pada suatu tingkat tertentu dalam kaitannya dengan tingkatan di atasnya, untuk memberikan urutan prioritas dari elemen-elemennya. Hasil penilaian ini akan lebih mudah disajikan dalam bentuk matriks pairwaise comparison atau matriks perbandingan berpasangan. Dalam membentuk pairwaise, Saaty (1980) menetapkan skala kuantitatif 1 sampai dengan 9 untuk menilai perbandingan tingkat kepentingan suatu elemen terhadap elemen lain (Tabel 1).

3. Logical Consistency

Logical consistency merupakan karakteristik penting AHP. Konsistensi memiliki dua makna, yang pertama adalah bahwa obyek-obyek yang serupa dapat dikelompokkan sesuai dengan keseragaman dan relevansi dan yang kedua adalah menyangkut tingkat hubungan antara objek-objek yang didasarkan pada kriteria tertentu. 
Tabel 1.

Tabel Comparative Judgement

\begin{tabular}{|c|c|}
\hline $\begin{array}{c}\text { Intensitas } \\
\text { kepentingan }\end{array}$ & Keterangan \\
\hline 1 & Kedua elemen sama pentingnya \\
\hline 3 & Elemen yang satu sedikit lebih penting daripada elemen yang lainnya \\
\hline 5 & Elemen yang satu lebih penting daripada elemen yang lainnya \\
\hline 7 & Satu elemen jelas lebih mutlak penting daripada elemen lainnya \\
\hline 9 & Jika untuk aktivitas i mendapat satu angka dibanding dengan \\
\hline kebalikan & aktivitas j, maka j mempunyai nilai kebalikannya dibanding dengan i \\
\hline
\end{tabular}

\section{PERANCANGAN SISTEM}

Urut proses pada sistem meliputi ::

1. Menentukan tujuan, kriteria, dan alternatif.

2. Menyusun kriteria-kriteria ke dalam bentuk matriks berpasangan.

3. Menjumlahkan matriks kolom.

4. Menghitung nilai elemen kolom kriteria dengan rumus masing-masing elemen kolom dibagi dengan jumlah matriks kolom.

5. Menghitung nilai prioritas kriteria dengan rumus menjumlah matriks baris hasil langkah ke-4 dan hasilnya dibagi dengan jumlah kriteria.

6. Menguji konsistensi setiap matriks berpasangan. Dengan langkah sebagai berikut:

- Menghitung Indeks Konsistensi (CI) dengan rumus:

$$
C I=\frac{\lambda \text { maksimum }-n}{n-1}
$$

Dimana:

$$
\begin{array}{ll}
\mathrm{CI} & =\text { indeks konsistensi } \\
\lambda \text { maksimum } & =\text { nilai eigen terbesar dari matriks berordo } \mathrm{n} . \\
\mathrm{n} & =\text { jumlah kriteria. }
\end{array}
$$

Nilai eigen terbesar didapat dengan menjumlahkan hasil perkalian jumlah kolom dengan vektor prioritas. 
- Menghitung Rasio Konsistensi (CR) dengan rumus:

$$
C R=\frac{C I}{R I}
$$

Dimana nilai Random Index (RI) berdasarkan perhitungan Saaty, dapat dilihat dari tabel 2.

Tabel 2.

Tabel Nilai Pembangkit Random (RI)

\begin{tabular}{|c|c|c|c|c|c|c|c|c|c|c|}
\hline $\mathrm{n}$ & 1 & 2 & 3 & 4 & 5 & 6 & 7 & 8 & 9 & 10 \\
\hline $\mathrm{RI}$ & 0.00 & 0.00 & 0.58 & 0.90 & 1.12 & 1.24 & 1.32 & 1.41 & 1.45 & 1.49 \\
\hline
\end{tabular}

7. Menyusun matriks baris antara alternatif versus kriteria yang isinya hasil perhitungan proses langkah 2 sampai dengan langkah 5.

8. Hasil akhirnya berupa prioritas global sebagai nilai yang digunakan oleh pengambil keputusan berdasarkan skor yang tertinggi.

Sistem prediksi ini memiliki 3 alternatif solusi yaitu kemenangan salah satu tim atau seri. Sistem ini memperhitungkan 4 kriteria utama untuk melakukan prediksi yaitu kualitas pemain, kualitas pelatih, semangat tim dan rekor pertemuan.

1. Kualitas pemain dihitung berdasarkan rata-rata nilai (point) kekuatan 18 pemain dalam satu tim. Setiap pemain diberi nilai berdasarkan atribut teknis, atribut mental dan atribut fisik. Atribut teknik meliputi kicking, attack, individual dan defensif. Atribut mental yang meliputi bravery, flair, workrate dan concentration. Atribut fisik yang meliputi strength dan agility. Nilai dari setiap pemain memiliki nilai maksimal 100.

2. Kualitas pelatih dihitung berdasarkan nilai (point) dari masing-masing pelatih tim. Penilaian kualitas pelatih didasarkan pada atribut coaching dan atribut mental. Atribut coaching yang meliputi attacking, defending, man management, mental serta tactical. Atribut mental yang meliputi adaptability, determination, level of discpline, tactical knowledge dan motivating. Nilai maksimum untuk kualitas pelatih adalah 100 .

3. Semangat tim dinilai dari 4 atribut utama yaitu rekor tiga pertandingan terakhir masing-masing tim sebelum bertanding (last three matches), kehadiran pelatih pada saat bertanding (coach instruction), ada tidaknya internal konflik yang terjadi dalam tim, pengaruh dari wasit yang bertugas dalam pertandingan (Refferee influence), dan faktor tuan rumah (home away). Masing-masing atribut bernilai maksimum 20 point sehingga total point adalah 100 .

4. Rekor pertemuan merupakan hasil-hasil pertandingan antara kedua tim saat mereka bertemu sebelum akan bertanding. Rekor pertemuan yang akan diambil dari tiga 
petemuan terakhir antara kedua tim tersebut. Penilaian yang dilakukan dapat dilihat pada tabel 3 .

Tabel 3.

Penilaian rekor pertemuan

\begin{tabular}{|c|c|c|c|c|}
\hline No & $M$ & $S$ & $K$ & $P$ \\
\hline 1 & 3 & 0 & 0 & 100 \\
\hline 2 & 2 & 1 & 0 & 83.3333 \\
\hline 3 & 2 & 0 & 1 & 66.6667 \\
\hline 4 & 1 & 2 & 0 & 66.6667 \\
\hline 5 & 1 & 1 & 1 & 50 \\
\hline 6 & 0 & 3 & 0 & 50 \\
\hline 7 & 1 & 0 & 2 & 33.3333 \\
\hline 8 & 0 & 2 & 1 & 33.3333 \\
\hline 9 & 0 & 1 & 2 & 16.6667 \\
\hline 10 & 0 & 0 & 3 & 0 \\
\hline \multicolumn{3}{|c|}{ M: Menang, S: Seri, K: Kalah, P: poin } \\
\hline
\end{tabular}

Pembobotan akhir pada sistem yang didasarkan pada 4 kriteria utama dapat dilihat pada tabel 4 .

Tabel 4.

Bobot kriteria

\begin{tabular}{|l|l|}
\hline \multicolumn{1}{|c|}{ Kriteria } & \multicolumn{1}{|c|}{ Bobot } \\
\hline Kualitas Pemain & 0.4181 \\
\hline Kualitas Pelatih & 0.2245 \\
\hline Semangat Tim & 0.2245 \\
\hline Rekor Pertemuan & 0.1330 \\
\hline
\end{tabular}

\section{IMPLEMENTASI DAN EVALUASI PROGRAM}

Sistem memiliki dua halam utama yaitu halaman untuk memasukan kriteria-kriteria untuk pembobotan dan halaman hasil yang merupakan halaman untuk menampilkan perhitungan AHP dan hasil prediksi dari sistem. Halaman utama sistem dapat dilihat pada Gambar 2 dan Gambar 3. Gambar 2 merupakan halaman untuk pengguna memasukkan tim yang akan bertanding dan informasi-informasi yang dibutuhkan untuk menghitung kualitas pemain, pelatih, semangat tim, dan rekor pertemuan untuk pertandingan yang akan berlangsung. Berdasarkan nilai dari 4 kriteria utama selanjutnya dilakukan pembobotan, perhitungan dengan metode AHP dan uji konsistensi dari kriteria yang dimasukan. Dalam melakukan pengujian Consistency Ratio (CR), didapati nilai $\mathrm{CR}$ yang konsisten $(\mathrm{CR}<10 \%)$. Setelah dilakukan perhitungan sebanyak dua iterasi, perbandingan tabel antara iterasi 1 dan 
iterasi 2 tidak berbeda jauh, sehingga bobot kriteria yang digunakan dapat dipastikan konsisten. Hasil pembobotan, matrik dan hasil akhir sistem dapat dilihat pada gambar 3.

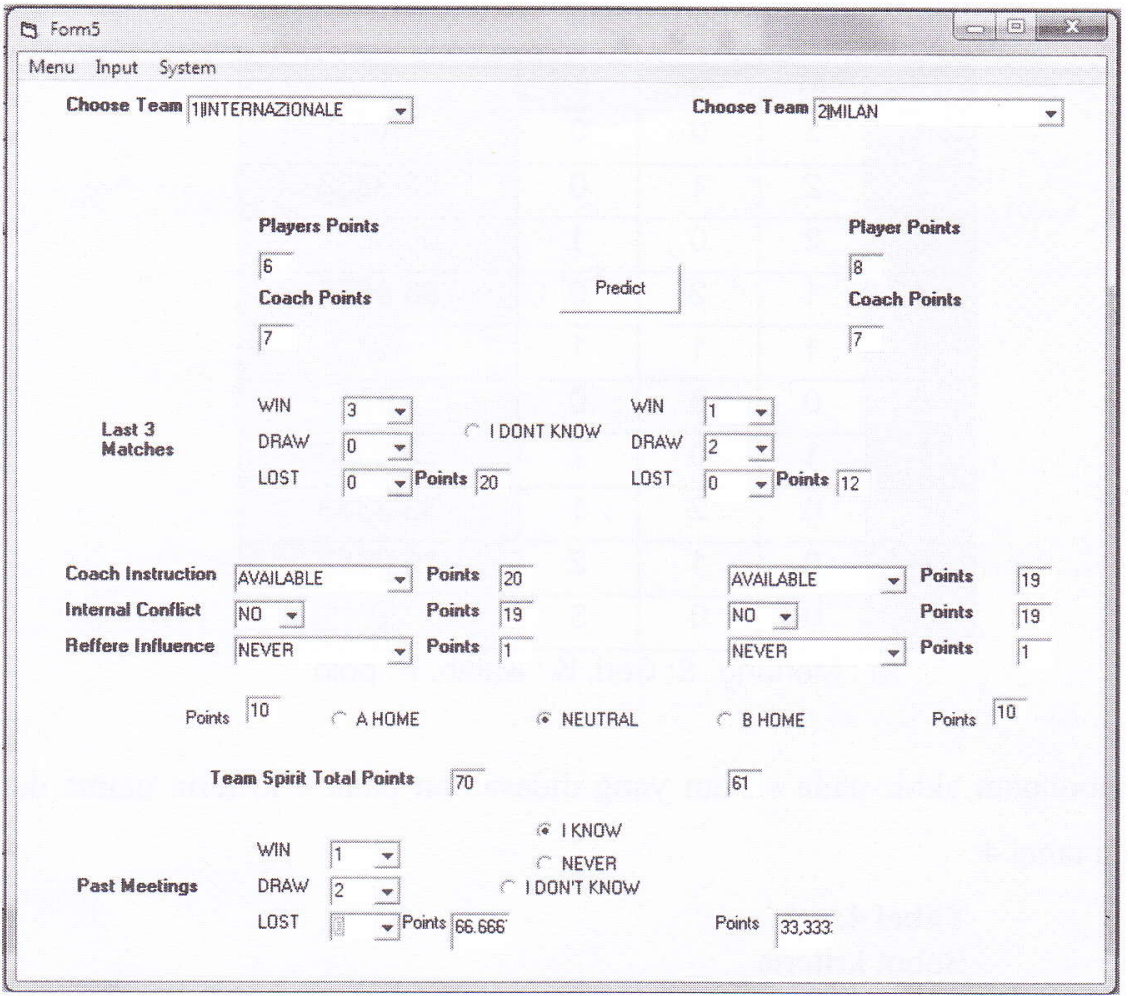

Gambar 2. Gambar menu utama

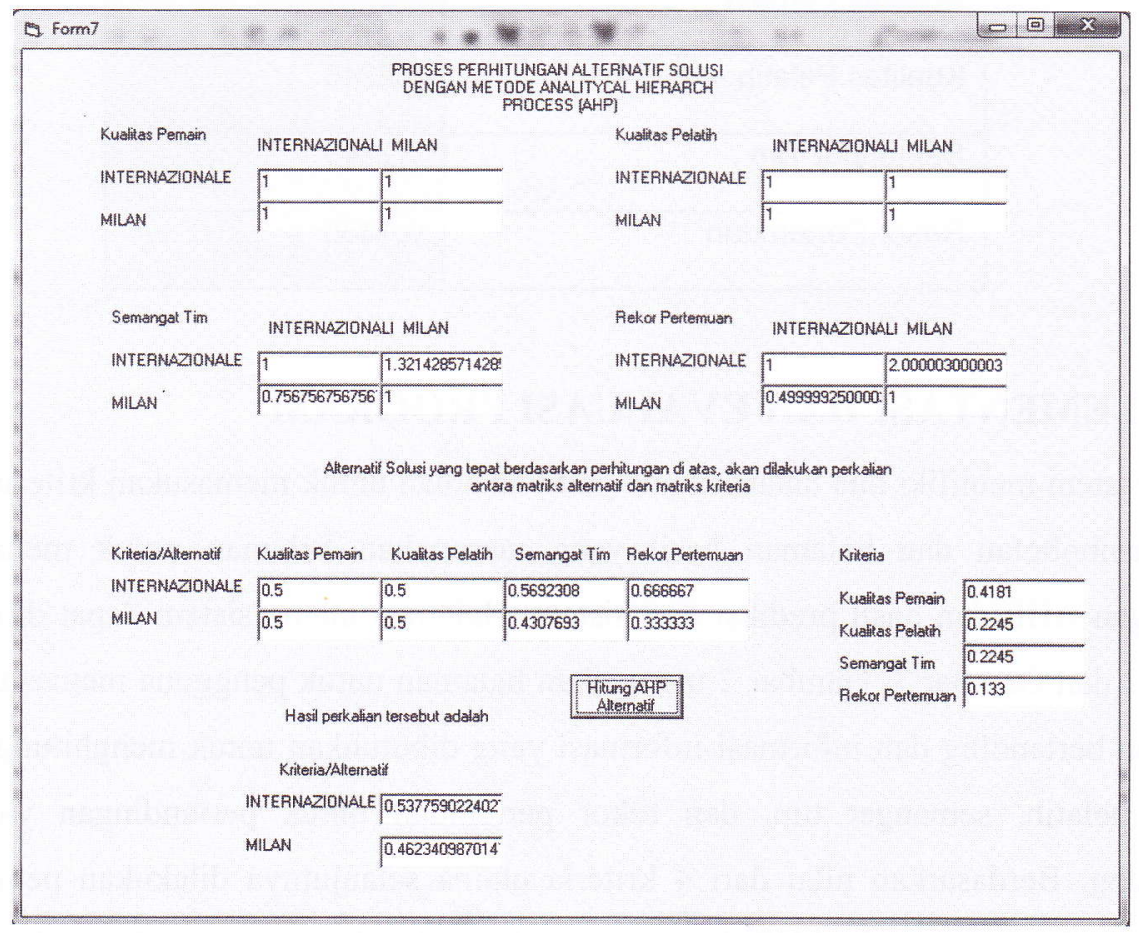

Gambar 3. Gambar menu proses dan hasil akhir 
Evaluasi sistem dilakukan untuk menguji tingkat akurasi sistem dalam melakukan prediksi terhadap hasil pertandingan sepak bola. Evaluasi dilakukan dengan menguji 25 pertandingan sepak bola yang pada musim 2011/2012 yang berlangsung di UEFA Champions League, Serie A dan La Liga. Hasil prediksi dapat dilihat pada Tabel 5, 6 dan 7. Berdasarkan hasil evaluasi dari 25 pertandingan yang ada didapatkan nilai rata-rata tingkat akurasi sistem dalam melakukan prediksi yaitu sebesar $80 \%$.

Tabel 5.

Tabel hasil pengujian sistem pada UEFA Champions League 2011/2012

\begin{tabular}{|l|l|l|l|}
\hline No & Nama Pertandingan & Hasil Nyata & Hasil Sistem \\
\hline 1 & Barca vs Milan (3/4/12) & $3-1$ & 0.1227 (Barca) \\
\hline 2 & Milan vs Barca (28/3/12) & $0-0$ & 0.0329 (Seri) \\
\hline 3 & Madrid vs Muenchen (17/4/12) & $2-1$ & 0.0541 (Madrid) \\
\hline 4 & Muenchen vs Madrid (25/4/12) & $2-1$ & 0.0455 (Muenchen) \\
\hline 5 & City vs Muenchen (7/12/11) & $2-0$ & 0.0264 (Seri) \\
\hline 6 & Muenchen vs City (27/9/11) & $2-0$ & 0.5658 (Muenchen) \\
\hline 7 & Barcelona vs Chelsea (24/4/12) & $2-2$ & 0.6885 (Barcelona) \\
\hline 8 & Chelsea vs Barcelona (18/4/12) & $1-0$ & 0.2204 (Seri) \\
\hline 9 & Chelsea vs Muenchen (19/5/12) & $1-1$ & 0.2033 (Seri) \\
\hline 10 & Milan vs Arsenal (15/2/12) & $4-0$ & 0.6654 (Milan) \\
\hline
\end{tabular}

Tabel 6.

Tabel hasil pengujian sistem pada Serie A Italy 2011/2012

\begin{tabular}{|l|l|l|l|}
\hline No & Nama Pertandingan & Hasil Nyata & Hasil Sistem \\
\hline 1 & Inter vs Milan (6/5/12) & $4-2$ & 0.0754 (Inter) \\
\hline 2 & Milan vs Inter (15/1/12) & $0-1$ & 0.5545 (Inter) \\
\hline 3 & Juventus vs Inter (25/3/12) & $2-0$ & 0.1955 (Juventus) \\
\hline 4 & Inter vs Juventus (29/10/11) & $1-2$ & 0.5487 (Juventus) \\
\hline 5 & Juventus vs Roma (22/4/12) & $4-0$ & 0.1343 (Juventus) \\
\hline 6 & Roma vs Juventus (12/12/11) & $1-1$ & 0.2441 (Seri) \\
\hline 7 & Milan vs Juventus (26/2/12) & $1-1$ & 0.1343 (Juventus) \\
\hline 8 & Juventus vs Milan (2/10/11) & $2-0$ & 0.6995 (Juventus) \\
\hline 9 & Roma vs Inter (5/2/12) & $4-0$ & 0.0245 (Seri) \\
\hline 10 & Inter vs Roma (17/9/11) & $0-0$ & 0.2015 (Seri) \\
\hline
\end{tabular}

Tabel 7.

Tabel hasil pengujian sistem pada La Liga Spanyol 2011/2012

\begin{tabular}{|l|l|l|l|}
\hline No & Nama Pertandingan & Hasil Nyata & Hasil Sistem \\
\hline 1 & Barca vs Madrid (22/4/12) & $1-2$ & 0.0879 (Madrid) \\
\hline
\end{tabular}


Tabel 7. (lanjutan)

Tabel hasil pengujian sistem pada La Liga Spanyol 2011/2012

\begin{tabular}{|l|l|l|l|}
\hline No & Nama Pertandingan & Hasil Nyata & Hasil Sistem \\
\hline 2 & Madrid vs Barcelona (10/12/11) & $1-3$ & 0.6546 (Barcelona) \\
\hline 3 & Madrid vs Valencia (8/4/12) & $0-0$ & 0.2669 (Seri) \\
\hline 4 & Valencia vs Madrid (19/11/11) & $2-3$ & 0.7783 (Madrid) \\
\hline 5 & Valencia vs Barcelona (22/9/12) & $2-2$ & 0.9548 rcelona) \\
\hline
\end{tabular}

\section{KESIMPULAN}

Penelitian menghasilkan beberapa kesimpulan yaitu :

a) Metode Analitycal Hierarchy Process (AHP) sesuai untuk digunakan dalam masalah prediksi hasil suatu pertandingan sepakbola dengan pembobotan kriteria kualitas pemain, kualitas pelatih, semangat tim dan rekor pertemuan.

b) Sistem memiliki tingkat akurasi sangat baik ( $80 \%$ ) yang dihitung berdasarkan hasil prediksi 25 pertandingan pada musin 2011/2012.

\section{Daftar Pustaka}

__, www.footballmanager.com/webmanual/fm2011, diakses pada tanggal 9 Desember 2011.

Kusrini. (2007). KONSEP dan APLIKASI SISTEM PENDUKUNG KEPUTUSAN. Yogyakarta : Andi Offset.

Saaty, T.L., (1995). The Analytic Hierarchy Process. New York : McGraw-Hill.

Suryadi, K., \& Ali, R. (1998). Sistem Pendukung Keputusan Suatu Wacana Struktural Idealisasi dan Implementasi Konsep Pengambilan Keputusan. Bandung: PT Remaja Rosdakarya.

Turban, Efraim. (1995). Decission Support System and Expert System. USA: Prentice Hall. 